\title{
Comparative Study of Platelet count and C-Reactive Protein among Gram Positive, Gram Negative and Fungal Sepsis in Newborns
}

\author{
Rabindran ${ }^{1}$, Parakh $\mathrm{H}^{2}$, Ramesh $\mathrm{JK}^{3}$, Reddy $\mathbf{P}^{4}$ \\ ${ }^{1}$ Dr Rabindran, Junior Consultant Neonatologist, ${ }^{2}$ Dr Hemant Parakh, Consultant Neonatologist, ${ }^{3}$ Dr Ramesh JK, \\ Consultant Pediatrician, ${ }^{4}$ Dr Prashant Reddy, Consultant Pediatrician, Sunrise Super specialty Children's Hospital, \\ Hyderabad, Andhra Pradesh, India
}

Address for correspondence: Dr Rabindran, E mail: rabindranindia@yahoo.co.in

\begin{abstract}
Introduction: Septicemia is characterized by positive blood culture, thrombocytopenia \& elevated C-reactive protein. Objective: To compare platelet indices and CRP among gram-positive, gram negative and fungal sepsis in newborns. Methods: This is a retrospective case analysis of 52 blood culture positive patients between January-2012 to December2014. The parameters examined were Baseline Platelet Count, Change In Platelet Count, (Baseline Platelet count- Change in Platelet count)/ Baseline Platelet Count, Platelet nadir, incidence, duration \& severity of Thrombocytopenia, baseline CRP, change in CRP, (baseline CRP- change in CRP)/ baseline CRP, CRP peak, incidence \& duration of raised crp. Statistical analysis: All data were collected in validated preformatted proforma sheet \& analysed using appropriate statistical methods. Results: Majority (61.53\%) had gram negative sepsis. Klebsiella was the commonest organism \& was isolated in $21.15 \%$ of babies. Weight of the baby $(\mathbf{p}=\mathbf{0 . 0 1 4})$, CRP Peak $(\mathbf{p}=\mathbf{0 . 0 3 4})$, incidence of high CRP $(\mathbf{p}=\mathbf{0 . 0 0 3})$, duration of high CRP $(\mathbf{p}=\mathbf{0 . 0 0 4}) \&$ duration of thrombocytopenia $(\mathbf{p}=\mathbf{0 . 0 0 1})$ differed significantly among gram-positive, gram negative \& fungal sepsis. Conclusion: We noted higher rise in CRP with prolonged duration following Gram negative sepsis. However the incidence of both raised CRP and thrombocytopenia were more among fungal sepsis. Though the onset was delayed, lower platelet nadir, more severe thrombocytopenia with prolonged duration was noted among fungal sepsis.
\end{abstract}

Key words: Platelet Count, C - reactive protein, Culture Positive Neonatal Sepsis

\section{Introduction}

Septicemia is a common cause of high neonatal mortality. It is characterized by positive blood culture, thrombocytopenia \& elevated C-reactive protein [1]. The term thrombocytopenia is referred to neonates with less than 150000 platelet count per micro liter which might be caused by less production or higher destruction of platelets or a combination of both mechanisms $[2,3,4]$. The thrombocytopenic patients are categorized according to their nadir: 1 to $1.5 \mathrm{lakh} / \mathrm{mm}^{3} ; 0.5$ to 1 lakh $/ \mathrm{mm}^{3} \&$ less than $50,000 / \mathrm{mm}^{3}$ [5].Values in normal range $\left(150000-400000 / \mathrm{mm}^{3}\right)$ can be considered as no risk of sepsis [6] .CRP is a biomarker and is elevated in sepsis [7- 11]. Normal CRP concentration in healthy neonates is usually lower than $6 \mathrm{mg} / \mathrm{L}$. Values more than this is considered as CRP Positive [12]. Blood culture is considered as the gold standard for the

Manuscript received: $25^{\text {th }}$ Dec 2014

Reviewed: $30^{\text {th }}$ Dec 2014

Author Corrected: $17^{\text {th }}$ Jan 2015

Accepted for Publication: $30^{\text {th }}$ Jan 2015 diagnosis of sepsis [13]. Based on the staining properties \& cell wall morphology, Bacteria are divided into Gram positive \& Gram negative. Whether the gram positive, gram negative bacteria or fungus have different effects on the depletion of platelet counts or the elevation of CRP is not clear [14]. We have conducted this study to compare platelet indices and CRP among gram-positive, gram negative and fungal sepsis in newborns.

\section{Methodology}

This is a retrospective case analysis of blood culture positive patients between January-2012 to December2014 in a single centre. Blood samples of all the patients included in this study were obtained for CBC, CRP levels and blood cultures. Name, date of admission, age, platelet count, CRP levels, blood culture reports were recorded on a data form. We enrolled 52 eligible neonates whose blood culture yielded positively for any 
organism. The data was analysed for differences in platelet count \& CRP in terms of Gram positive, Gram negative \& Fungal microorganisms causing sepsis. All neonates included in this study received appropriate antibiotics or antifungal medications.

Unit protocol for Investigation of Neonatal Sepsis: Soon after admission two ml blood sample was taken in EDTA vacutainer \& was processed for Platelet count. Blood was collected for blood culture in BD BACTEC bottles \& cultured in Sabouraud's Dextrose agar \& Brain Heart Infusion Broth and colony growth was observed. Also $1 \mathrm{ml}$ blood sample was taken for qualitative estimation of CRP. Direct counting of platelets in an improved Neubauer's Chamber was done. Platelet count less than 1.5 Lakh / cumm was considered abnormal. CRP in serum was estimated by CRP TurbiLatex Kit using Latex turbimetry. Test showed positivity when CRP value was more than $6 \mathrm{mg} / \mathrm{L}$. Smears were made from peripheral blood and stained by Leishmans stain and examined to confirm thrombocytopenia.The platelet count \& CRP used for this study was the one obtained at the same time as the positive blood culture or the one closest to the time the positive blood culture was drawn.

Interventions: Management of neonatal sepsis as per standard unit protocol. The study was approved by the Hospital Research and Ethics Committee.

Definition of Parameters: The parameters that were examined in this study were

Baseline Platelet Count: Platelet count obtained at least 24 hours before the time that the positive blood culture was obtained.

Change In Platelet Count: Platelet count at the time of onset of sepsis.

Baseline Platelet Count- Change In Platelet Count)/ Baseline Platelet Count: Drop in platelet count at the time of onset of sepsis as compared with the baseline platelet count obtained at least 24 hours before the time that the positive blood culture was obtained.

Platelet Nadir: Lowest platelet count obtained during a 20-day period starting from the time the initial positive blood culture was drawn.

Incidence of Thrombocytopenia: Number of episodes with platelet nadir of less than $150000 / \mathrm{mm}^{3}$ during a 20-day period starting from the time the initial positive blood culture was drawn.

Duration of Thrombocytopenia: Number of continuous days that the platelet count remained less than $150000 / \mathrm{mm}^{3}$. If the neonate had no Thrombocytopenia, the duration was considered to be zero.

Severity of Thrombocytopenia:

No Thrombocytopenia - Platelet count more than $150000 / \mathrm{mm}^{3}$

Mild Thrombocytopenia - Platelet count between 100000 to $150000 / \mathrm{mm}^{3}$

Moderate Thrombocytopenia - Platelet count between 50000 to $100000 / \mathrm{mm}^{3}$

Severe Thrombocytopenia - Platelet count less than $50000 / \mathrm{mm}^{3}$

Baseline CRP: CRP obtained at least 24 hours before the time that the positive blood culture was obtained.

Change in CRP: CRP obtained at the time of onset of sepsis.

(Baseline CRP- Change IN CRP)/ Baseline CRP: Rise in CRP at the time of onset of sepsis as compared with a baseline CRP obtained at least 24 hours before the time that the positive blood culture was obtained.

CRP Peak: Highest CRP obtained during a 20-day period starting from the time the initial positive blood culture was drawn.

Incidence of Raised CRP: Number of episodes with a CRP more than $6 \mathrm{mg} / \mathrm{L}$ obtained during a 20 -day period starting from the time the initial positive blood culture was drawn.

Duration of High CRP: Number of continuous days that the CRP remained more than $6 \mathrm{mg} / \mathrm{L}$. If the patient had no raised CRP, the duration was considered to be zero.

Statistical Analysis: All the data were collected in validated preformatted proforma sheet and analysed using software Statistical Package for Social Sciences. Categorical variables were analyzed using Chi-square analysis with Yates correction. Student' $t$ ' test was used to compare the means. A p-value of $<0.05$ was considered significant. Analysis of variance was used to compare groups \& data were expressed as mean \pm standard deviation. 


\section{Results}

Table 1: Distribution of Organisms Isolated In Culture Positive Sepsis

\begin{tabular}{|c|c|c|c|}
\hline TYPE & & No. & $\%$ \\
\hline BACTERIA & GRAM NEGATIVE & 32 & $61.53 \%$ \\
\hline BACTERIA & GRAM POSITIVE & 14 & $26.92 \%$ \\
\hline \multirow[t]{2}{*}{ FUNGAL } & & 6 & $11.53 \%$ \\
\hline & ORGANISM ISLOATE & & \\
\hline \multirow{2}{*}{ NEGATIVE } & KLEBSIELLA & 11 & $21.15 \%$ \\
\hline & ACINETOBACTER & 9 & $17.30 \%$ \\
\hline POSITIVE & STAPHYLOCOCCUS & 9 & $17.30 \%$ \\
\hline FUNGAL & CANDIDA & 6 & $11.53 \%$ \\
\hline POSITIVE & ENTEROCOCCUS & 5 & $9.61 \%$ \\
\hline \multirow[t]{5}{*}{ NEGATIVE } & PSEUDOMONAS & 4 & $7.69 \%$ \\
\hline & E.COLI & 3 & $5.76 \%$ \\
\hline & BURHKOLDERIA & 2 & $3.84 \%$ \\
\hline & ELIZABETHAE KINGELLA & 2 & $3.84 \%$ \\
\hline & H.PARAINFLUENZA & 1 & $1.92 \%$ \\
\hline
\end{tabular}

Out of the 52 babies with culture positive sepsis; majority (61.53\%) had gram negative sepsis. Klebsiella was the commonest organism and was isolated in 11 babies (21.15\%). History of Maternal PIH was noted in $27.87 \%$ among babies with gram negative sepsis, $16.66 \%$ among fungal sepsis \& $7.19 \%$ among gram negative sepsis.

The mean weight \pm standard deviation among fungal sepsis was $1.55 \pm 0.67$; among Gram negative sepsis was $2.02 \pm$ 0.87 ; among Gram positive sepsis was $2.63 \pm 0.61$ (Anova $\mathbf{p}=\mathbf{0 . 0 1 4}$; significant).

Fungal sepsis was more common in babies with lower weight. The mean CRP Peak \pm standard deviation among fungal sepsis was $61.33 \pm 37.26$; among Gram negative sepsis was $56.84 \pm 32.03$; among Gram positive sepsis was $30.21 \pm$ 32.09(Anova $\mathbf{p}=\mathbf{0 . 0 3 4}$; significant). Fungal sepsis had higher CRP peak.

The mean incidence of high CRP \pm standard deviation among fungal sepsis was $3 \pm 0.89$; among Gram negative sepsis was $3.03 \pm 1.37$; among Gram positive sepsis was $1.5 \pm 1.45$ (Anova $\mathbf{p}=\mathbf{0 . 0 0 3}$; significant). Fungal \& Gram negative sepsis had more incidence of raised CRP as compared to Gram positive sepsis.

The mean Duration of high CRP \pm standard deviation among fungal sepsis was $7.83 \pm 3.18$; among Gram negative sepsis was $7.96 \pm 3.83$; among Gram positive sepsis was $3.92 \pm 3.45$ (Anova p= 0.004; significant). Fungal \& Gram negative sepsis had more prolonged duration of raised CRP as compared to Gram positive sepsis.

The mean Duration of Thrombocytopenia \pm standard deviation among fungal sepsis was $9.5 \pm 1.04$; among Gram negative sepsis was $5.4 \pm 3.63$; among Gram positive sepsis was $2.64 \pm 1.31$ (Anova p= 0.001; significant). Fungal sepsis had more prolonged Thrombocytopenia as compared to Gram positive \& Gram negative sepsis. 
Table 2: CRP and Platelet Variations among Fungal, Gram Negative \& Gram Positive Sepsis

\begin{tabular}{|c|c|c|c|c|c|c|c|c|c|}
\hline S.N & FACTOR & $\begin{array}{l}\text { LEVENE'S } \\
\text { TEST P }\end{array}$ & ANOVAP & $\begin{array}{l}\text { FUNGAL } \\
\text { MEAN }\end{array}$ & $\begin{array}{l}\text { FUNGAL } \\
\text { SD }\end{array}$ & $\begin{array}{c}\text { GRAM } \\
\text { NEGATIVE } \\
\text { MEAN }\end{array}$ & $\begin{array}{c}\text { GRAM } \\
\text { NEGATIVE } \\
\text { SD }\end{array}$ & $\begin{array}{c}\text { GRAM } \\
\text { POSITIVE } \\
\text { MEAN }\end{array}$ & $\begin{array}{c}\text { GRAM } \\
\text { POSITIVE } \\
\text { SD }\end{array}$ \\
\hline 1 & AGE IN DAYS & 0.546 & 0.345 & 10 & 10.46 & 4.87 & 7.37 & 5.28 & 7.79 \\
\hline 2 & GESTATION IN WEEK & 0.001 & 0.059 & 34.83 & 2.63 & 34.18 & 3.44 & 26.57 & 1.98 \\
\hline 3 & WEIGHT IN Kg & 0.009 & 0.014 & 1.55 & 0.67 & 2.02 & 0.87 & 2.63 & 0.61 \\
\hline 4 & BASELINE CRP & 0.947 & 0.058 & 3.16 & 5.3 & 4.9 & 13.46 & 4.71 & 7.27 \\
\hline 5 & CHANGE IN CRP & 0.063 & 0.124 & 23 & 25.49 & 46.34 & 32.15 & 30.21 & 32.09 \\
\hline 6 & $\begin{array}{c}\text { (BASELINE-CHANGE) / } \\
\text { BASELINE CRP }\end{array}$ & 0.144 & 0.145 & 0.87 & 0.05 & 0.87 & 0.19 & 0.74 & 0.26 \\
\hline 7 & CRP PEAK & 0.801 & 0.034 & 61.33 & 37.26 & 56.84 & 32.03 & 30.21 & 32.09 \\
\hline 8 & INCIDENCE HIGH CRP & 0.313 & 0.003 & 3 & 0.89 & 3.03 & 1.37 & 1.5 & 1.45 \\
\hline 9 & DURATION HIGH CRP & 0.875 & 0.004 & 7.83 & 3.18 & 7.96 & 3.83 & 3.92 & 3.45 \\
\hline 10 & BASELINE PLATELET COUNT & 0.171 & 0.157 & 2.01 & 0.17 & 2.15 & 0.71 & 2.53 & 0.7 \\
\hline 11 & CHANGE IN PLATELET & $<0.001$ & 0.054 & 0.57 & 0.11 & 1.25 & 0.7 & 1.51 & 1.04 \\
\hline 12 & $\begin{array}{c}\text { (BASELINE-CHANGE) / } \\
\text { BASELINE PLATELET }\end{array}$ & 0.057 & 1.677 & 0.62 & 0.25 & 0.42 & 0.21 & 0.43 & 0.31 \\
\hline 13 & PLATELET NADIR & 0.001 & 0.06 & 0.54 & 0.1 & 1.05 & 0.81 & 1.49 & 1.02 \\
\hline 14 & $\begin{array}{c}\text { INCIDENCE } \\
\text { THROMBOCYTOPENIA }\end{array}$ & 0.04 & 0.053 & 3.16 & 0.75 & 2.46 & 1.98 & 1.28 & 1.48 \\
\hline 15 & $\begin{array}{c}\text { DURATION } \\
\text { THROMBOCYTOPENIA }\end{array}$ & 0.012 & 0.001 & 9.5 & 1.04 & 5.4 & 3.63 & 2.64 & 3.36 \\
\hline 16 & $\begin{array}{c}\text { SEVERITY } \\
\text { THROMBOCYTOPENIA }\end{array}$ & 0.016 & 0.079 & 2.5 & 0.54 & 1.78 & 1.18 & 1.21 & 1.31 \\
\hline
\end{tabular}

Analysis of variance was used to compare the groups, and data was expressed as mean \pm standard deviation

Weight of the baby $(\mathbf{p}=\mathbf{0 . 0 1 4})$, CRP Peak $(\mathbf{p}=\mathbf{0 . 0 3 4})$, incidence of high CRP $(\mathbf{p}=\mathbf{0 . 0 0 3})$, Duration of high CRP ( $\mathbf{p}=$ 0.004) \& Duration of Thrombocytopenia $(\mathbf{p}=\mathbf{0 . 0 0 1})$ differed significantly among gram-positive, gram negative sepsis \& fungal sepsis.

Figure 1: CRP and Platelet Variations among Fungal, Gram Negative \& Gram Positive Sepsis

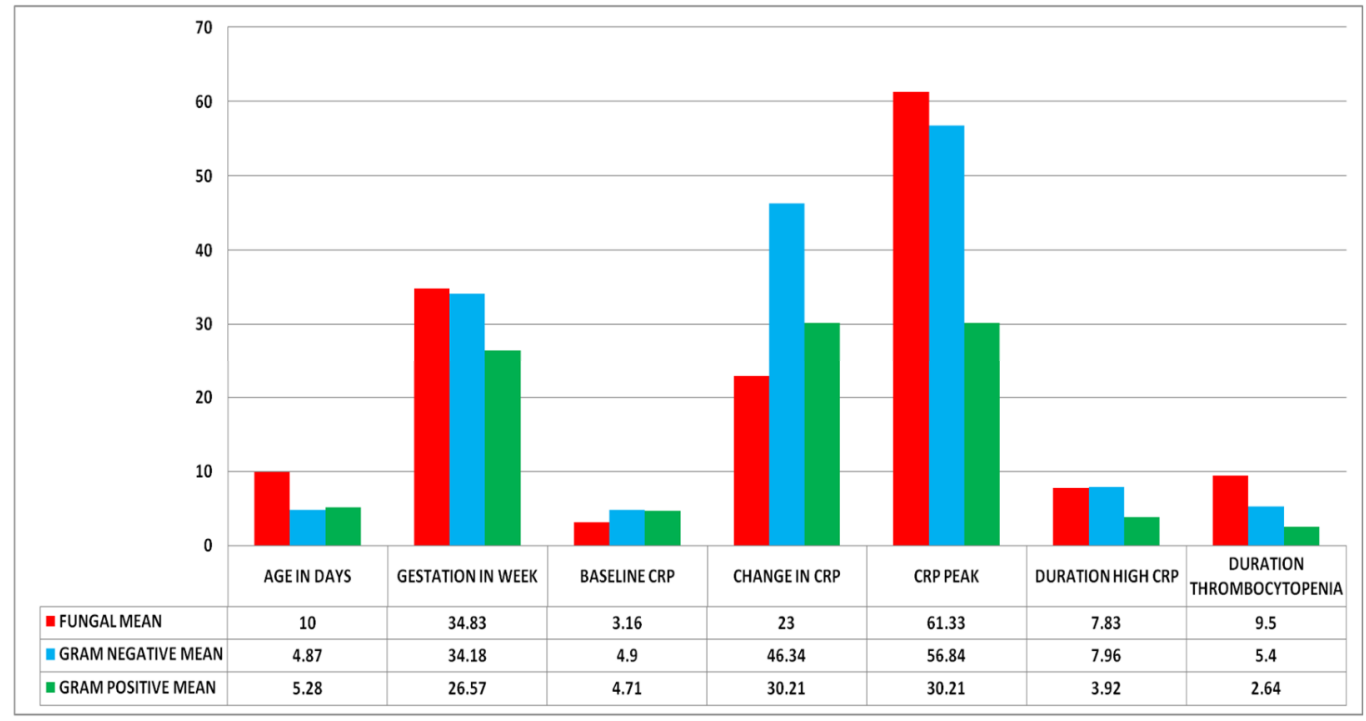


Figure 2: CRP and Platelet Variations a Fungal, Gram Negative \& Gram Positive Sepsis

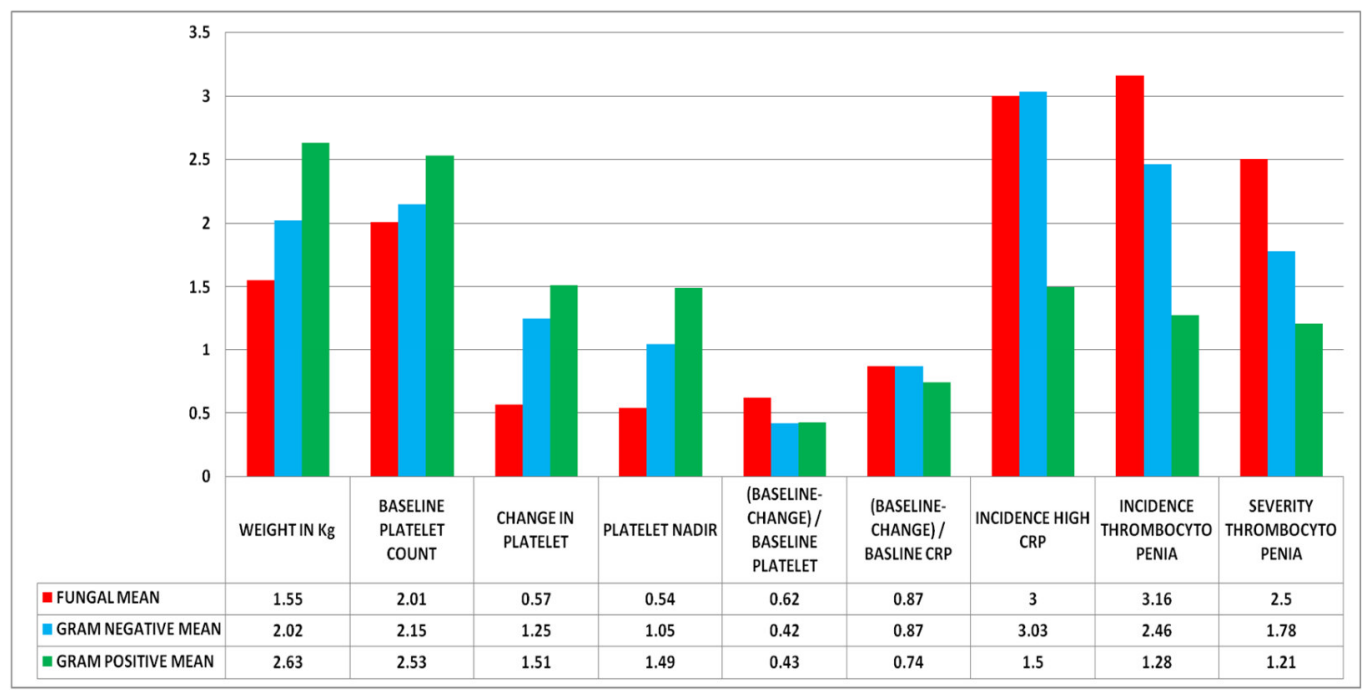

\section{Discussion}

In our study majority (61.53\%) had gram negative sepsis. Kyoung Hee Choi et al.[14], Mehmet Yekta Oncel et al [15], Abdalla Alshorman et al[16] also noted predominantly gram negative sepsis in $84.47 \%, 54.3 \%$ $\&$ in $52.4 \%$ neonates respectively. However Guida et al. in his study observed that majority $(76 \%)$ had gram positive sepsis, only $16 \%$ had gram negative sepsis \& $8 \%$ had fungal sepsis $[17,18]$. In our study Klebsiella was the commonest organism and was isolated in $21.15 \%$ of babies. Mhada TVet al [19], Viswanathan R SA et al [20], Vallance Het al [21], Sankar MJ et al [22] \& Qazi Iqbala,b et al [23] also noted Klebsiella pneumoniae as the commonest organism. However Deepa et al [24] \& Kayange N et al [25] in their study noted that Staphylococcus aureus was the commonest. Kuruvilla KA et al noted that E.coli was the most common causative bacteria [26]. This variation in the predominant organism causing neonatal sepsis can be attributed to the different study populations \& study periods. Specific platelet responses to different infectious agents have not been extensively characterized [17].

CRP \& Platelet variations among fungal, gram negative \& gram positive sepsis:

We noted delayed onset of culture positive sepsis among fungal sepsis. In our study the Change in CRP was high in Gram negative sepsis $(46.34 \pm 32.15)$ as compared to fungal sepsis $(23 \pm 25.49) \&$ Gram positive sepsis (30.21 \pm 32.09$)$. Kyoung Hee Choi et al in his study noted that that the mean CRP among culture positive sepsis was $75.25 \pm 18.52 \mathrm{mg} / \mathrm{L}$ [14]. We observed that the CRP peak was higher in fungal sepsis $(61.33 \pm$ $37.26)$ as compared to Gram negative sepsis (56.84 \pm $32.03)$ \& Gram positive sepsis $(30.21 \pm 32.09)$. Kyoung Hee Choi et al in his study noted that that the mean CRP among culture positive sepsis was $75.25 \pm 18.52$ $\mathrm{mg} / \mathrm{L}[14]$. Chiesa C et al.[27], Hofer Net al.[28], Alexandraki I et al.[29], N.Laxmi et al.[30], M.Khassawaneh et al.[31] \& Z.Ahamed et al.[32] also noted that the C-reactive protein was higher in gram negative bacteria than gram positive bacterial sepsis. Kyoung Hee Choi et al. in his study noted that that the mean CRP among culture positive sepsis was $75.25 \pm$ $18.52 \mathrm{mg} / \mathrm{L}$ [14]. Kyoung Hee Choi et al.[14] \& Blanco et al.[33] noted that the mean CRP of Gram negative sepsis did not differ significantly when compared to gram positive sepsis. On the contrary Nuutia et al. found higher CRP level in Gram positive sepsis than Gram negative sepsis [34].

In our study, the incidence of raised CRP was more among fungal sepsis $(3 \pm 0.89) \&$ Gram negative sepsis $(3.03 \pm 1.37)$ as compared to Gram positive sepsis (1.5 $\pm 1.45)$. Similarly the duration of raised CRP was prolonged in fungal sepsis $(7.83 \pm 3.18)$ \& Gram negative sepsis $(7.96 \pm 3.83)$ as compared to Gram positive sepsis $(3.92 \pm 3.45)$. We observed that the duration of high CRP was prolonged in Gram negative sepsis $(7.96 \pm 3.83)$ as compared to fungal sepsis (7.83 $\pm 3.18)$ \& Gram positive sepsis $(3.92 \pm 3.45)$. We noted that the drop in platelet count was more in fungal sepsis $(0.57 \pm 0.11)$ as compared to Gram negative sepsis (1.25 $\pm 0.7) \&$ Gram positive sepsis $(1.51 \pm 1.04)$. Deepa et 
al.[24] \& Kyoung Hee Choi et al.[14] in their study noted that the Platelet counts' mean value in culture positive sepsis was $1.735 \times 10^{5}$ and $0.88 \times 10^{5}$ respectively. Abdalla Alshorman et al.[16], Guida et al.[17], Qazi Iqbala b et al.[23] \& Charoo BA et al.[35] also noted that gram negative and fungal sepsis had a significantly lower platelet count compared to gram positive sepsis.

In our study the Platelet nadir was lower in fungal sepsis $(0.54 \pm 0.1)$ as compared to Gram negative sepsis (1.05 $\pm 0.81) \&$ Gram positive sepsis $(1.49 \pm 1.02)$. Kyoung Hee Choi et al.[14] also noted that the platelet count of Gram negative sepsis $(0.67 \pm 0.341)$ was significantly less when compared to gram positive sepsis (1.98).

Kyoung Hee Choi et al.[14] \& Rowe et al.[36] observed normal platelet count in gram positive sepsis. On the contrary Guida et al. found thrombocytopenia in Gram positive sepsis [18]. We noted higher incidence of Thrombocytopenia among fungal sepsis $(3.16 \pm 0.75)$ when compared to Gram negative sepsis $(2.46 \pm 1.98) \&$ Gram positive sepsis $(1.28 \pm 1.48)$. Abdalla Alshorman et al[16], Guida et al.[17], Qazi Iqbala $b$ et al.[23], Charoo BA et al.[35], Modanlou HD et al.[37], Storm W et al.[38] \& Escobar GJ. Et al.[39] also noted that gram negative and fungal sepsis had increased incidence of thrombocytopenia as compared to gram positive sepsis. However Manzoni et al. noted that there was no significant difference in the incidence of thrombocytopenia among fungal, gram negative \& gram positive sepsis [40].

We observed that the duration of Thrombocytopenia was prolonged among fungal sepsis $(9.5 \pm 1.04)$ as compared to Gram negative sepsis $(5.4 \pm 3.63) \&$ Gram positive sepsis $(2.64 \pm 1.31)$. Abdalla Alshorman et al.[16], Guida et al.[17], Qazi Iqbala b et al.[23], Charoo BA et al.[35] noted that fungal and gram negative had more prolonged thrombocytopenia compared to gram positive sepsis. In our study the degree of thrombocytopenia was severe among fungal sepsis $(2.5$ $\pm 0.54)$ when compared to Gram negative sepsis $(1.78 \pm$ $1.18) \&$ Gram positive sepsis $(1.21 \pm 1.31)$.

Benjamin et al. also showed that fungal sepsis is associated with a greater degree of thrombocytopenia than is seen with staphylococcal sepsis [41]. However Rowe et al. found that $71 \%$ with Gram-negative sepsis had platelet counts $<100000 / \mathrm{mm}^{3}$, whereas all of the platelet counts in the non septic or Gram-positive sepsis patients were $>150000 / \mathrm{mm}^{3}[36]$.
Summary: We noted greater rise in CRP \& prolonged duration of raised CRP following Gram negative sepsis. However the incidence of both raised CRP and thrombocytopenia were higher among fungal sepsis. Though the onset of thrombocytopenia was delayed, lower platelet nadir, more severe thrombocytopenia \& prolonged duration of thrombocytopenia was noted among fungal sepsis.

\section{Conclusion}

In the present study, we have shown that there are quantitative differences in the platelet response and CRP to infection with the 3 major categories of organisms causing sepsis. The hematological parameters - Platelet Count and CRP constitute a simple, quick, cost effective and readily available tool for the prompt management of culture positive neonatal sepsis.

\section{Funding: Nil}

Conflict of interest: None initiated.

\section{Permission from IRB: Yes}

\section{References}

1. Dhananjay BS, Sunil Kumar Nandaa. Comparison of Biochemical and Pathological markers in neonates with Sepsis and neonates without Sepsis; International Journal of Biological \& Medical Research. 2011; 2(4): $1131-1134$.

2. Van den Hof MC, Nicolaides KH. Platelet count in normal, small, and anemic fetuses. American Journal of Obstetrics \& Gynecology.1990;162(3):735-9.

3.Sola-Visner M, Saxonhouse MA, Brown RE. Neonatal thrombocytopenia: what we do and don't know. Early Human Development. 2008;84(8):499-506.

4. Sprung CL, Peduzzi PN, Shatney CH, Schein RM, Wilson MF, Sheagren JN, Hinshaw LB. Impact of encephalopathy on mortality in the sepsis syndrome. The Veterans Administration Systemic Sepsis Cooperative Study Group. Critical Care Medicine. 1990;18(8):801-6.

5. Vincent JL, Moreno R, Takala J, Willatts S, De Mendonça A, Bruining H, et al. The SOFA (Sepsisrelated Organ Failure Assessment) score to describe organ dysfunction/failure. On behalf of the Working Group on Sepsis-Related Problems of the European 
Society of Intensive Care Medicine. Intensive Care Medicine. 1996;22(7):707-10.

6. McKenzie SB(1996a). Normal hematological values ; McKenzie.S B. Text book of haematology 2nd edition. Baltimore ;Williams \& wilkins

7. Chiesa C, Paner A, Osborn J. Diagnosis of neonatal sepsis : A clinical and laboratory challenge. Clinical Chemistry. 2004; 10: 279-287.

8. Franz AR, Kron M, Pohlandt F, Steinbach G. Comparison of procalcitonin with interleukin 8, Creactive protein and differential white blood count for the early diagnosis of bacterial infections in newborn infants. Pediatric infectious disease Journal. 1999. 18, 666-671.

9. Pacifico L, Panero A, Colarizi P, Matrunola M, Simonetti AF, Chiesa C: Neonatal Candida albicans septic thrombosis of the portal vein followed by cavernous transformation of the vessel. Journal of Clinical Microbiology 2004, 42(9):4379-4382.

10. Nuntnarumit $\mathrm{P}$, Pinkaew $\mathrm{O}$, Kitiwanwanich $\mathrm{S}$ : Predictive values of serial C-reactive protein in neonatal sepsis. Journal of Medical Association Thailand 2002, 85 Supplement 4:S1151-1158.

11. Bipin K: Evaluation of serum C-reactive Protein in diagnosis and prognosis of neonatal septicemia. Paediatrics 2013, 4(7):WMC001643.

12. I Roberts, N A Murray. Neonatal thrombocytopenia: causes and management, Archives of Diseases of Childhood, Fetal Neonatal Edition 2003;88:F359F364 doi:10.1136/fn.88.5.F359

13. Haque KN. Neonatal Sepsis in the Very Low Birth Weight Preterm Infants: Part 2: Review of Definition, Diagnosis and Management. Journal of Medical Sciences. 2010;3(1):11-27.

14. Kyoung Hee Choi, Sung Soo Rim, Byung Min Moon,Ki Bok Kim.Study on platelet counts and indices in neonates ; Korean Journal of Pediatrics 1996 March; 39(3) :338-345.

15. Mehmet Yekta Oncel, Ramazan Ozdemir, Sadik Yurttutan, Fuat Emre Canpolat, Omer Erdeve, Serife Suna Oguz, Nurdan Uras, Ugur Dilmen. Mean Platelet Volume in Neonatal Sepsis ; Journal of Clinical Laboratory Analysis 26: 493-496 (2012).
16. Abdalla Alshorman et al. The Effect of Neonatal Sepsis on Platelet Count and their Indices ; Journal of Medicine 2008; June: Vol. 42(2).

17. Jack D. Guida, Anette M. Kunig, Kathleen H. Leef, Steven E. McKenzie, David A. Paul. Platelet Count and Sepsis in Very Low Birth Weight Neonates: Is There an Organism-Specific Response? Pediatrics 2003; 111:1411-1415.

18. Stoll BJ, Hansen N, Fanaroff AA, Wright et al. Lateonset sepsis in very low birth weight neonates: the experience of the NICHD Neonatal Research Network. Pediatrics, 2002, 110: 285-291.

19. Mhada TV, Fredrick F, Matee MI, Massawe A: Neonatal sepsis at Muhimbili National Hospital, Dar es Salaam, Tanzania; aetiology, antimicrobial sensitivity pattern and clinical outcome. BMC public health 2012, 12(1):904.

20. Viswanathan R SA, Ghosh C, Dasgupta S, Mukherjee S, Basu S: Profile of neonatal septicaemia at a district-level sick newborn care unit. Journal of health, population, and nutrition 2012 30(1):41-48.

21. Vallance H, Lockitch G: Rapid, semi-quantitative assay of C-reactive protein evaluated. Clinical Chemistry 1991, 37(11):1981-1982.

22. Sankar MJ AR, Deorari AK, Paul VK.: Sepsis in the newborn. Indian Journal of Pediatrics 2008,75(3): 261266.

23. Qazi Iqbala b, Charoo Bashira, Sheikh Mushtaqa, Asif Ahmada and Akhtar Rasool Babaa. Thrombocytopenia and other hematological parameters in culture positive neonatal sepsis and their impact ; Journal of Pediatric Infectious Diseases 8 (2013) 25-29 25 DOI 10.3233/JPI-130371.

24. Deepa S, Manjunatha MR, Venkatesha D. Screening cord blood is a better diagnosing method for early onset neonatal septicemia; Indian Journal of Medical Research and Pharmaceutical Sciences, October 2014; 1(5) ISSN: $2349-5340$.

25. Kayange N, Kamugisha E, Mwizamholya DL, Jeremiah S, Mshana SE: Predictors of positive blood culture and deaths among neonates with suspected neonatal sepsis in a tertiary hospital, Mwanza-Tanzania. BMC pediatrics 2010, 10(1):39. 
26. Kuruvilla KA, Pillai S, Jesudasan M, Jana AK. The bacterial profile of sepsis in a neonatal unit in south India. Indian Paediatrics 1998; 35:851-58.

27. Chiesa C, Signore F, Assumma M, Buffone E, Tramontozzi P, Osborn JF, Pacifico L. Serial measurements of C-reactive protein and interleukin- 6 in the immediate postnatal period: reference intervals and analysis of maternal and perinatal confounders. Clinical Chemistry 2001, 47(6):1016-1022.

28. Hofer N, Zacharias E, Müller W, Resch B: An update on the use of C-reactive protein in early-onset neonatal sepsis. Neonatology 2012, 102(1):25-36.

29. Alexandraki I, Palacio C: Gram-negative versus Gram-positive bacteremia: what is more alarming?. Critical care (London, England) 2010, 14(3):161.

30. Lakshmi N, Guru Raj Kumar A. C - reactive protein In Neonatal Sepsis. Journal of Indian Microbiology, 1992, 10(1): 29-31.

31. Khassawneh M, Hayajneh WA, Kofahi H, Khader Y, Amarin Z, Daoud A. Diagnostic Markers for Neonatal Sepsis: Comparing C-reactive Protein, Interleukin-6 and Immunoglobulin M . Scandinavian Journal of Immunology, 2007, 65(2): 171-175.

32. Ahmed Z, Ghafoor T, Waqar T, Ali S, Aziz S, Mahmud S Diagnostic value of $\mathrm{C}$ - reactive protein and hematological parameters in neonatal sepsis. Journal of College of Physicians \& Surgeons,Pakistan, 2005, 15 (3):152-156.

33. Blanco A, Solis G, Arranz E, Coto GD, Ramos A T. Serum levels of CD14 in neonatal sepsis by Grampositive and Gram-negative bacteria. Acta Paediatrica, 2008, 85(6):728-732.
34. Nuutila J, Jalava-Karvinen P, Hohenthal U, Laitinen I . CRP/CD11b ratio: a novel parameter for detecting Gram-positive sepsis. Human Immunology Journal, 2009, 70(4):237-243.

35. Charoo BA, Iqbal JI, Iqbal Q, Mushtaq S, Bhat AW, Nawaz I.Nosocomial sepsis induced late onset thrombocytopenia in a neonatal tertiary care unit: a prospective study. Hematology Oncology Stem Cell Therapy Journal 2009; 2:349-53.

36. Rowe MI, Buckner DM, Newmark S. The early diagnosis of Gram negative septicemia in the pediatric surgical patient. Annals of Surgery. 1975;182:280-286.

37. Modanlou HD, Ortiz OB. Thrombocytopenia in neonatal infection. Clinical Pediatrics. 1981;20:402-407

38. Storm W. Use of thrombocytopenia for the early identification of sepsis in critically ill newborns. Acta Paediatrica. 1982;23:349-355

39. Escobar GJ. The neonatal "sepsis work-up" personal reflections on the development of an evidence-based approach toward newborn infections in a managed care organization; Pediatrics 1999; 103: 360-373.

40. Manzoni P, Mostert M, Galletto P, Gastaldo L. Is thrombocytopenia suggestive of organism-specific response in neonatal sepsis? Pediatrics 2009; 51:206-10.

41. Benjamin DK, Ross K, McKinney RE, Benjamin $\mathrm{DK}$, Auten R, Fisher RG. When to suspect fungal infection in neonates: clinical comparison of Candida albicans and Candida parapsilosis fungemia with coagulase negative staphylococcal bacteremia. Pediatrics. 2000; 106:712-718.

\section{How to cite this article?}

Rabindran, Parakh H, Ramesh JK, Reddy P . Comparative Study of Platelet count and C-Reactive Protein among Gram Positive, Gram Negative and Fungal Sepsis in Newborns. Int J Med Res Rev 2015;3(2):149-156. doi: 10.17511/ijmrr.2015.i2.026. 